\title{
A Study of College English Follow-up Module Teaching from the Perspective of Needs Analysis
}

\author{
Li Lanjie*, Zhan Ying, Zhang Yuxuan \\ Xi' an Research Institute of Hi-Tech, Xi'an, China \\ Email address: \\ dream1011@126.com (Li Lanjie), sarahzy2005@sina.com (Zhan Ying), shootingstar0715@126.com (Zhang Yuxuan) \\ ${ }^{*}$ Corresponding author
}

\section{To cite this article:}

Li Lanjie, Zhan Ying, Zhang Yuxuan. A Study of College English Follow-up Module Teaching from the Perspective of Needs Analysis. Science Innovation. Vol. 5, No. 3, 2017, pp. 138-143. doi: 10.11648/j.si.20170503.13

Received: March 10, 2017; Accepted: April 17, 2017; Published: April 20, 2017

\begin{abstract}
Needs analysis plays an essential role in designing courses and provides the basis for choosing teaching objectives, teaching content, textbooks, teaching methods and evaluating teaching effects. The study is based on a questionnaire survey among 775 non-English undergraduate majors who have passed CET4 or CET6 test with the help of needs analysis and module teaching theories. It obtains information about students' needs for follow-up college English courses in the aspects of their purposes of learning English, the teaching content and modes of follow-up courses and the like. On the basis of the analysis of the survey, the study summarizes the current problems existing in the follow-up module teaching, and then puts forward a tentative framework for needs collection and response, teaching material resources, teaching time, examinations and evaluation, and extracurricular activities of College English follow-up module teaching courses, in order to provide some useful reference for college English reform nationwide.
\end{abstract}

Keywords: Needs Analysis, Follow-up Module Teaching, Study

\section{基于需求分析理论的大学英语四级后续模块化教学的调查研究}

李兰杰, 战盈, 张语轩

理学院外语教研室, 火箭军工程大学, 西安, 中国

邮箱

dream1011@126. com（李兰杰）, sarahzy2005@sina.com（战盈）, shootingstar0715@126.com（张语轩）

摘要: 需求分析是课程设计时必须考虑的重要因素, 也是教师制定教学目标、决定教学内容、选择使用教材、确定教学 方法、评估教学结果等组织教学的重要依据。本研究基于需求分析理论和模块化教学模式, 对我校775位已经通过大学 英语四级考试的非英语专业本科学生开展了问卷调查, 了解到学生通过大学英语四级考试之后对于后续英语课程学习 目的、教学内容、教学模式等方面的需求。通过对调查结果进行分析, 总结了模块化教学取得的成绩和存在的三个方 面的问题, 并就需求收集与响应机制、教学保障资源体系、教学时间、考试评价体系和第二课堂活动等五方面提出改 进建议，以期为全国大学英语教学改革提供借鉴。

关键词: 需求分析, 后续模块化教学, 调查 


\section{1. 引言}

近年来, 随着我国社会经济的发展和国际交流的增多, 英语受到愈来愈多的重视, 学生学习英语的年龄逐渐提前, 渠道越来越多, 老师的教学水平也随之提升, 学生的整体 英语水平有了大幅提高。以笔者所教授的2013级通信工程 专业班级为例, 他们2013年8月份入学, 2014年6月份参加 大学英语四级考试, 全班 43 人, 37 人通过四级考试, 首次 四级通过率达到 $86 \%$ 。2007年教育部公布的《大学英语课 程教学要求》 (以下称《课程要求》) 中提到: “各高等 学校应根据实际情况, 按照《课程要求》和本校的大学英 语教学目标设计出各自的大学英语课程体系, 将综合英语 类、语言技能类、语言应用类、语言文化类等必修课程和 选修课程有机结合, 确保不同层次的学生在英语应用能力 方面得到充分的训练和提高。”[1]

在这种背景下, 为顺应全国大学英语教学改革的趋势, 我校从2013年秋季学期开始实施分级教学, 2015年春季学 期开始在 2013 级非英语专业学生第四学期的英语教学中 实施大学英语四级后续模块化教学。改革总体上对拓展学 生英语听说能力、鼓励个性化发展、提高语言综合运用能 力起到了明显的积极作用, 但也发现了不少问题, 亟待研 究改进。

\section{2. 开设大学英语四级后续模块化教学的理论依 据}

基于需求分析理论的大学英语四级后续模块化教学 是指非英语专业本科生通过大学英语四、六级考试之后, 学校根据《课程要求》的规定, 参照学生的需求和教学资 源现状, 开设高阶段的语言学习模块课程供学生选修, 让 这些学生按照他们的需求或兴趣学习大学英语。这是一种 多元而个性化的英语教学, 其主要依据是需求分析理论和 模块化教学模式。

\section{1 . 需求分析理论}

在教学领域, 需求分析（needs analysis）是指通过 观察、访谈或调查问卷等途径研究分析需求而使用的方法 技术 [2]。Hutchinson与Water将需求分为目标需求和学习 需求, 目标需求包括必学的知识、欠缺的知识和想学的知 识, 学习需求涵括学习环境、学习者知识、学习者技能、 学习策略及学习动机等 [2]。对外语教学而言, 需求分析 是设计、设置和实施语言课程必要的起始步骤。很多学者 都非常重视需求分析理论的研究, 如王海啸 (2004) 认为 在个性化大学英语教学大纲设计时需要注重分析需求, 管 春林（2005）阐述了需求分析对经贸方向英语专业课程设 置的意义和方法, 蔡基刚（2012）探讨了基于需求分析的 大学ESP课程模式等。束定芳 (2004) 认为需求分析可以 为制定外语教育政策和设置外语课程, 为外语课程的内容、 设计和实施, 为外语教学目的和教学方法与为现有外语课 程的检查和评估提供依据和参考 [3]。

学生学习EGP (English for General Purposes, 通 用英语) 到达一定程度之后, 如通过大学英语四、六级考
试之后, 需要学习ESP (English for Specific Purposes, 专门用途英语）或者其它实用性、职业性、技能性比较高 的课程, 以满足社会、个人对于较高语言综合运用能力的 需求。不仅如此, 《课程要求》中也指出 “大学英语教学 应贯彻分类指导、因材施教的原则, 以适应个性化教学的 实际需要。各高等学校应根据本校实际情况确定教学目标, 并创造条件, 使那些英语起点水平较高、学有余力的学生 能够达到较高要求或更高要求。”[1]根据新的课程要求, 大学英语四级后续教学课程的目标应该是帮助学生达到 较高要求或更高要求, 进一步提高学生的英语综合应用能 力, 学生学习的目标也不再是通过大学英语四、六级考试, 而是能够学以致用, 努力满足毕业后在工作和社会交往中 对于英语各项技能的需求。因此, 大学英语四级后续教学 在内容设计、课程设置上应当以尽力满足学生个性化和多 样化的学习需求为导向, 在设置课程时充分考虑社会和学 生的实际需求, 为我国的经济发展和国际交流需求培育高 质量应用型人才。

\section{2. 模块化教学}

“模块” 的概念最早于1976年由美国达特茅斯学院感 知神经学研究中心主任迈克尔・加扎尼加 (Michael Gazzaniga）教授提出, 他认为: “脑是由在神经系统的 各个水平上进行活动的子系统以模块的形式组织在一起 的。” [4]模块理论最早应用在工业生产中, 即把功能相 关的工具零件组合成模块, 使其整体功能大于部分功能之 和。在教学领域, 模块理论是将一门学科中或各门学科中 具有同类功能的知识点或技能项组合成知识模块或能力 模块, 使其整体功能大于部分功能之和。

模块化教学是指根据已经确定的教学能力培养目标, 将内在联系密切、学习方式要求和教学目标相近的课程内 容整合在一起, 形成若干模块, 分别实现整体教学目标中 不同的分目标。模块化教学的基本理念是在一定时间内组 织学生按照一定的目标进行学习。胡壮麟总结该模式具有 以下三个方面的优点: 一, 将英国教育制度的严格和深度 与美国教育制度的灵活和宽度妥善结合; 二, 学生可以根 据自己的英语水平、进度和兴趣学习, 充分发挥潜力; 三, 学生可以在学习英语过程中学习不同学科的知识。模块化 教学使语言技能知识、真实情境和实际运用语言能力三者 之间得到了统一。[5]

\section{3. 模块化教学的课程设置}

在需求分析理论和模块化教学理论的基础上, 结合 《课程要求》的规定, 我校自 2013年秋季学期起在全校范 围内开展大学英语教学改革, 在前三个学期根据学生的语 言水平实施分级教学, 即进行大学英语基础模块一一听、 说、读、写等基本语言技能模块的教学, 在第四个学期也 就是二年级春季学期, 根据社会和学生的需求分析和教学 资源现状, 设置多个高阶段语言模块如翻译、军事英语、 文化等课程供学生选修。具体实施方案如下:

新生军训结束后首先进行英语摸底考试, 结合高考英 语成绩打破专业限制对学生进行重新分班, 选拔 30 人左右 
成绩优秀者编入快班, 剩余学生基本按照 $2: 1$ 的比例在本 旅内分别编入普通班和慢班。

按照教学改革计划, 普通班学生和慢班学生从《新视 野大学英语1》 (第三版) 开始学习, 第二学期完成《新 视野大学英语 $2 》$ 的学习后参加全国大学英语四级考试。 快班学生则从《新视野大学英语 2 开始学习, 第一册书 留给他们自主学习使用, 第一学期结束后即可参加四级考 试, 通过者第二学期结束后可以参加六级考试。快班学生 的英语起点水平高, 对教学内容和教学进度上有明显不同 于普通班和慢班学生的需求, 因此在第三个学期, 快班英 语教师可根据学生的实际需求、自己的特长或研究方向以 及现有的教学资源, 为学生选择一门英语模块 (如英汉翻 译, 英美文化, 科技论文写作等模块), 每周四个学时, 开拓学生的视野, 满足他们对于英语学习的较高要求。

在第四学期, 学校为所有学生开设多样化英语模块。 未过四级的学生编入四级强化班继续进行基础语言模块 的学习; 对已过四级的学生模块化教学, 我校进行了两种 模式的尝试。第一种模式是模块化课程设置主要分为《英 美文化》、《英汉翻译》和《军事英语》。上课形式为教 授同一学员旅的教师分别准备上述三门课的每门12学时 内容, 同一学院的学生轮流参加三门课程的学习, 教师把 12 学时的课程教授三遍。第二种模式将模块化教学课程调 整为《英汉翻译》和《军事英语》两个模块。其中《军事 英语》模块包括军事英语阅读和军事英语视听说两个部分。 上课形式也改为学生选择一个模块进行一学期的学习, 不 再轮流, 教师也就两个模块之一准备 34 学时的内容, 给固 定的学生讲授。根据学期末的调查访谈等了解, 学生对于 第二种模式接受程度相对较高, 教学效果也更好。

\section{4. 问卷调查与数据分析}

\section{1 . 问卷调查的主要内容}

为了解我校学生通过大学英语四级考试之后对于大 学英语课程的学习需求, 及其对模块化教学课程设置、教 学模式等的看法, 特设计了一份问卷调查。问卷的问题主 要包括: (1)学生学习大学英语的目的; (2)学生对大学英语 课程有哪些需求; (3)愿意选修哪些大学英语四级后续模块 化教学课程; (4)学生对大学英语后续模块化教学的学时设 置、教材选用、教学方式、考核评价等有什么看法; (5)学 生对EGP和ESP的有什么认识等。

\section{2. 数据收集}

问卷调查于 2016 年 3 月在 2014 级所有教学班随机发放, 掌握了每个班级通过大学英语四级考试的具体人数, 了解 大学生在通过大学英语四级考试之后对于后续英语课程 的需求。同时, 还对大学英语任课教师进行了访谈, 以了 解教师对后续模块化教学的看法认识、教学准备情况、教 学实施过程中曾遇到的困难以及对以后的大学英语四级 模块化教学的建议等等, 方便调查者全面了解模块化教学 的实施情况。

\section{3. 数据分析}

本次问卷调查的对象是我校 2014 级非英语专业各旅 营已经通过大学英语四级或六级考试的学生, 共发放调查 问卷800份, 收回问卷783份, 有效问卷775份, 其中通过 四级的人数为 607 人, 通过六级的人数为 168 人。

以下是对部分问题调查结果的描述与分析:

表1 你学习大学英语的目的是。

\begin{tabular}{lll}
\hline 选项 & 人数 & 比例 $(\%)$ \\
\hline A. 对英语感兴趣, 可以拓宽视野, 了解西方文化 & 181 & 23.4 \\
与概况 & 401 & 51.7 \\
B. 拿到学位证书 & 107 & 13.8 \\
C. 打算继续深造, 为以后查阅外文资料做准备 & 43 & 5.6 \\
D. 观看英语电影, 欣赏英文歌曲 & 9 & 1.2 \\
E. 为日后工作做准备 & 33 & 4.3 \\
F. 将来周游世界 &
\end{tabular}

从表1可以看出, 对于学习大学英语的目的, 有 $51.7 \%$ 的学生认为其学习大学英语是因为学校规定必须通过大 学英语四级考试, 毕业时才能拿到学位证书; 有 $23.4 \%$ 的 学生学习英语是因为对英语感兴趣, 希望通过英语学习拓 宽自己的视野, 更方便了解英语国家的文化概况; 有 $13.8 \%$ 的学生学习英语是因为日后打算考研继续深造, 为以后查 阅外文资料打基础; 还有 $5.6 \%$ 的学生学英语是为了更好地 观看英语电影视频, 欣赏学习英文歌曲, $4.3 \%$ 的学生是为 了将来能够周游世界, $1.2 \%$ 的学生为了以备日后工作的需 要。由此可知学生学习大学英语的内在动力不足, 主要是 来自学校给予的外部动力。很多学生对于大学英语学习的 目标认识存在偏差, 对于英语这门人文学科没有足够的重 视。此外与教师座谈了解到, 学校的英语课程设置和教师 本身的授课内容与方式也一定程度造成了学生目前大学 英语的学习状态。

尽管有大约一半的学生对于大学英语的学习动力不足, 或许正是源于对目前大学英语教学的不满意, 有 $67.9 \%$ 的学 生对于大学英语四级后续模块化教学表示欢迎, 认为有必 要开设后续英语课程。他们对于后续英语课程的需求如表 2 所示。愿意选修能够提高具体技能的英语课程的学生人数 比例最高, 达到 $29.2 \%$ 。第四和第五两个选项加起来共有 40. $4 \%$ 的学生愿意学习与军事或自己专业相关的英语, 还有 $21.8 \%$ 的学生愿意选修自己感兴趣的英语课程, 有 $5.4 \%$ 的学 生希望通过继续对英语课程的学习, 可以帮助他们通过大 学英语六级的考试。由此可以看出, 开设大学英语四级后 续模块化教学非常有必要, 可以更好地激发学生学习英语 的兴趣和动力, 并且能够进一步更有针对性地提高他们的 英语运用能力, 这正好可以实现《课程要求》里关于让起 点较高、学有余力的学生达到较高或更高要求的规定。

表2 通过大学英语四级后你对英语课程的需求是。

\begin{tabular}{lll}
\hline 选项 & 人数 & 比例 $(\%)$ \\
\hline A. 继续目前的课本学习 & 25 & 3.2 \\
B. 选修提高具体听说读写译等技能的课程 & 226 & 29.2 \\
C. 选修自己感兴趣的英语课程 & 169 & 21.8 \\
D. 学习与自己专业相关的英语 & 101 & 13.0 \\
E. 选修与军事相关的英语课程 & 212 & 27.4 \\
F. 辅导通过六级考试 & 42 & 5.4 \\
\hline
\end{tabular}


表3 你最希望选修的 $2 门$ 英语课程是。

\begin{tabular}{lll}
\hline 选项 & 人数 & 比例 $(\%)$ \\
\hline A. 新视野大学英语 (四) & 43 & 5.5 \\
B. 英美文化 & 178 & 23.0 \\
C. 英美文学 & 106 & 13.7 \\
D. 公共演讲与辩论 & 96 & 12.4 \\
E. 翻译理论与实践 & 234 & 30.2 \\
F. 写作 & 87 & 11.2 \\
G. 跨文化交际 & 105 & 13.5 \\
H. 军事英语阅读 & 138 & 17.8 \\
I. 军事英语视听说 & 221 & 28.5 \\
J. 新闻英语视听说 & 84 & 4.4 \\
K. 商务英语 & 55 & 7.1 \\
L. 英美概况 & 97 & 12.5 \\
M. 与专业相关的专门用途英语 & 102 & 13.2 \\
N. 你的建议 & 4 & 0.5 \\
\hline
\end{tabular}

从表 3 可以看出, 最受欢迎的两门课程分别为翻译理 论与实践和军事英语视听说, 分别有 234 名学生 (30.2\%) 和 221 名学生 $(28.5 \%)$ 愿意选修这两门课程, 其次是英美 文化和军事英语阅读, 选择的人数比例为 $23 \%$ 和 $17.8 \%$ 。作 为军校的学生, 他们没有像地方大学的学生那样关注日后 工作的需要, 所以像商务英语这种在地方大学比较热门的 课程在军校成了少有人问津的冷门, 而对于某项技能的现 实需求和对军事英语的兴趣是军校学生更倾向的选择。这 为我校开设四级后续模块化教学指引了方向。

对于是否有必要开设与专业相关的专门用途英语课 程, 超过一半 (58.5\%) 的学生是持肯定观点的。但关于 开设该类课程的时间, $38.2 \%$ 的学生认为通过四级考试之 后可以进行专门用途英语课程的学习; $25.7 \%$ 的学生认为 通过六级考试后再开设专门用途英语课程比较合适; 也有 19. 5\%的学生认为大二第一学期就可以开设专门用途英语 课程。可见, 大部分学生对通用英语和专门用途英语之间 关系的认识是正确的, 即通用英语的学习目的是打好语言 的基础, 只有语言基础比较夯实, 达到一定的英语水平, 才能向专门用途英语的方向发展, 才能比较好地掌握专业 英语。

表4 你希望通过四、六级后的英语模块化教学的模式是。

\begin{tabular}{lll}
\hline 选项 & 人数 & 比例 $(\%)$ \\
\hline A. 课堂讲授 & 47 & 6.1 \\
B. 自主学习 & 129 & 16.6 \\
C. 课堂讲授与自主学习相结合 & 523 & 67.5 \\
D. 专题讲座 & 76 & 9.8 \\
E. 你的建议 & 0 & 0 \\
\hline
\end{tabular}

在775名被调查的学生中, 多达523名学生希望英语模 块化教学的教学是课堂讲授与自主学习相结合, 选择教师 课堂讲授这种传统教学模式的学生仅为 47 人。由此可以看 出, 当前时期的大学生对于自主学习的意愿日益强烈, 越 来越不满足于传统教师课堂教授的教学模式。但是学生还 没有到达可以彻底脱离教师进行完全自主学习的地步, 所 以目前比较理想的教学模式是课堂教授与自主学习相结 合。

总体而言, 对调查问卷 15 个问题的结果统计分析之后 发现: 学生对大学英语四级后续模块化教学内容的需求呈 现出多样、个性但又相对集中的特点。首先, 有 $83 \%$ 的学
生认为, 为已经通过大学英语四、六级的学生根据他们的 需求和兴趣开设后续模块化英语课程是有必要的。其次, 分别有 $30 \%$ 左右的学生愿意选择提高具体技能的课程以及 与军事相关的英语课程, 他们的选择即个性又比较集中。 第三, 对于开设与他们专业相关的专门用途英语课程的时 间, 学生有的认为通过四级就可以开设, 有的认为通过六 级再开设, 还有些认为确定某个学期不管是否已经通过四、 六级考试, 都可以开设专门用途英语。最后, 对于授课模 式的选择反映了学生集中化的特点, 课堂教学与自主学习 相结合是他们普遍接受的模式。

\section{4 . 结果与讨论}

\section{4. 1. 模块化教学取得的效果}

模块化教学是我校贯彻《课程要求》中规定的 “分类 指导、因材施教的原则, 以适应个性化教学的实际需要” 的表现 [1]。我校根据自己的学校类型、治学定位和人才 培养目标等实际情况确定教学目标, 设置课程创造条件, 使那些英语起点较高、学有余力的学生结合自己的兴趣特 点, 进行自主选择学习课程, 最大限度地调动其的学习积 极性和主动性, 加强自己某方面的弱项, 或者彰显某方面 的特长, 从而能够达到较高要求或更高要求。对于英语教 师, 模块化教学为其提供了提高自身教学能力的机会和更 透彻展示自己英语专业技能的平台。模块化教学这种新型 教学模式, 能够促进教师进行教学素材的积累, 教学资源 的整合, 教学方法的探索和科研方向的开拓。

\section{4.2. 模块化教学存在的问题}

大学英语四级后续模块化教学实施过程中也暴露出 一些问题, 主要表现在:

(1) 掌握需求不系统, 开设课程不全面。由于开设 四级后续模块化教学在我校还是新鲜事物, 之前只是对个 别班级进行了解, 没有进行大范围系统的问卷调查以了解 学生的需求, 学生对自身的实际需求也还比较模糊和零碎, 加之教学方案中对四级通过前的教学与四级通过后进行 的模块化教学之间的衔接过渡缺乏系统设计, 导致学生对 于所开设的课程满意度不高。如2014年开设的《英美文化》, 教师授课前也顾虑到, 如果讲授得太宽泛, 学生大多已经 了解, 没有教学的必要, 进行系统专业化的讲授, 则因为 学时数量和学生英语水平有限又无法展开。因学生普遍反 映该课程没有开设必要, 因此该课程在试验一年后取消。 另外有学生反映想要报考六级, 但没有六级辅导课程, 进 行模块化教学只能练习某方面的技能, 比如 《英汉翻译》 课程虽然可以提高其翻译能力, 却忽略了听力技能的训练。 后来2015年进行了全年级较大范围的调查问卷, 才比较全 面清楚地了解了学生学习大学英语的目的和需求、对大学 英语后续模块化教学的学时设置、教材选用、教学方式、 考核评价等的看法。

（2）选用教材不恰当，教学资源不丰富。市面上适 合非英语专业学生的文化类、翻译类或者军事类英语教材 非常有限, 且针对性不强, 因此学校决定由任课教师自编 教材。但因为时间有限, 教材在使用过程中还是存在不少 问题, 比如难易程度不完全适合学生的英语水平, 配套教 
材资源不足等, 尤其是《军事英语视听说》, 学生希望教 师能在课上或者课下提供更多、更新、更适合他们水平的 音视频影音资料, 实际上这些教学资料的收集、整理、校 对和上线都需要大量人力、物力和时间, 短期内很能实现。

（3）开课时间不完整，考核方式不规范。由于12月 份的大学英语四级考试成绩要到次年的 3 月份才公布, 而 我校春季学期一般2月份就开始上课, 英语课程开学之初 便开始上课, 所以四级成绩出来之前, 没有办法进行模块 化教学。我校采取的方法是第一个月还是原来的自然班, 上课仍旧以《新视野大学英语》第四册为主。四级成绩公 布后, 再分为已过四级与未过四级两类, 已过四级的学生 选择模块化教学。这种衁尬的开课时间导致期末考试的时 候还必须加上课本上的内容。开设的两种模块化教学, 第 一学年考试由于学生三个模块都进行了学习, 所以考试试 卷为统一考试试题。第二学年由于学生选择了不同的模块, 所以试题分开进行考试。但是因为试卷难易不好把握, 期 末成绩差异稍大, 不便于学习效果的横向对比分析。

\subsection{3. 改进的建议}

为了进一步改善大学英语四级后续模块化教学, 提高 大学英语教学改革实效, 提出以下几点建议:

(1) 建立系统化持续化的需求收集与响应机制。为 确保课程设置的合理性, 在需求收集对象上, 应对更大范 围的学生进行座谈、访谈和问卷调查, 精心设置谈话提纲 或问卷内容, 充分利用数理统计工具对需求收集的大样本 结果数据进行科学分析, 找出根本性、共同性、一般性需 求, 提高需求收集的系统性。另外, 充分利用校园网互动 教学平台应建立需求持续收集机制, 根据学员听课过程中 反映的新需求, 有针对性做好各模块内容调整。重新设置 问卷的形式和内容, 除了解学生对于想学知识的需求, 还 可以了解他们不想再学的方面, 一并进行分析, 尽可能地 多开设一些满足学生需求、适合学生水平和发挥教师优势 的课程, 以求最大限度地满足学生的需求。实现 “因需而 教”, 以达到更好的教学效果。

（2）合作构建更丰富合理的教学保障资源体系。在 教材的使用上, 更全面地进行市场调查, 如有已公开出版 且难度合适的教材, 可以直接使用。否则, 建议西安地区 非专业类英语教学院校组织精干力量合作编写自编教材, 由各院校教师按照分工进行教学资源的搜集和整理, 加强 教材编写和教材内容的不断更新。通过各院校教学保障条 件建设经费分工建设教学资源网络平台, 可离线或在线访 问, 方便学生课下进行自主学习。针对课堂教学无法完全 满足学生个性化学习需求的实际问题, 建立适于学生自主 学习的模块化教学专业教室, 促进学生在课堂外更加有针 对性地按需获取知识。此外, 教师还应注意搜集与学生专 业密切相关的教学材料, 尽力逐步使模块化课程满足学生 对于ESP尽可能多的学习需求。

(3) 合理安排教学时间。建议国家适当调整英语四 级考试和成绩公布时间。最理想的成绩公布时间是新学期 开始之前或之初, 这样有利于这个学期的计划和安排。如 果因为阅卷成绩统计需要时间, 个人认为适当把考试时间 向前推几个星期, 这样避开较冷较热的时间, 或许更有利 于学生的开始发挥。在国家调整英语四级考试前, 在排课
时间安排上, 尽力与教务部门沟通, 可以选择第四学期的 大学英语课程等四级成绩出来之后再开课, 或者一开始进 行模块化教学试听, 四级成绩出来之后再重新选择确定班 级。

（4）调整完善考试评价体系。在考试评价上, 继续 采用终结性评价与形成性评价相结合, 但英语教师可根据 模块内容, 按照平时成绩至少占总成绩 $30 \%$ 的要求, 灵活 设置平时成绩的参考内容 (如可以设置为课堂表现 $10 \%$, 平时作业 $10 \%$, 小组学习 $10 \%$ 等)。在考核试卷使用之前, 认真进行试做, 尽量保证试卷难易程度相当。此外, 为了 增强分级教学和模块化教学的系统性和科学性, 尤其是为 了确保考试的公平性和公正性, 可以逐步建立不同模块相 应的试题库, 并在以后的教学中完善试题库, 期末考试时 可以直接从试题库进行选题测试。

(5) 开展更多丰富多彩的第二课堂活动。大学英语 第二课堂是对课堂英语教学的有益拓展。在教室里, 学生 大多都是为了通过考试而学习, 缺乏把学习英语各项技能、 提高英语综合应用能力作为学习目标的动力和环境。通过 第二课堂开展丰富多样的交互性活动, 可以为学生创造良 好的英语学习环境, 把课内教学和课外活动进行有机结合, 可以进一步激发学生的学习兴趣, 拓展他们的学习空间, 为其英语学习创造更多的机会和平台, 有利于巩固和提高 课堂内的教学效果, 发展学生的个性, 对提高学生的自主 学习能力和英语综合运用能力有着非常重要的辅助作用, 对四级后续模块化教学的顺利开展和效果强化有明显的 促进作用。

\section{5. 结论}

大学英语教学改革自2003年就开始实施, 历经几次变 革, 目前认为大学英语教学的方向是: 重视语言交流交际 能力的培养, 通过开展计算机网络教学, 发展学生的自主 学习能力等, 从 “培养语言技能为主要目标” 的课程设置 转为 “培养语言技能加专业知识为主要目标” 的课程设置, 母的是培养综合型复合型的英语人才。虽然大学英语教学 改革顺应了社会发展的要求, 但这种自上而下的改革模式 必须结合学生这个学习主体的群体的内在需求才能真正 实现改革的目的, 获得理想的教学效果。因此了解学生学 习大学英语的目的, 对于英语课程的需求非常关键。

大学英语四级后续模块化教学尤其需要了解分析学 生学习英语的需求, 才能有针对性地进行教学设计和实施 教学。这种模块化教学在我校目前还处于尝试阶段, 虽然 经过两年的教学试验, 取得了一些较好的教学效果, 但在 这个过程中也遇到不少问题。除了提出的五条改进建议, 还有一点不容忽视, 那就是教师队伍的建设, 因为模块化 教学这种改革涉及学生、教师、教材、教学资源、教学目 标、教学模式、教学内容、教学方法、教学管理等许多因 素。为了实现四级后模块化教学的最终目的, 即满足学生 技能兴趣等方面的需要, 让学生在通过大学英语四级之后 能在英语听、说、读、写、译等方面能有较大的提高, 需 要教师与教务部门加强合作共同努力, 使模块化教学逐步 完善, 为大学英语教学改革提供借鉴。 


\section{参考文献}

[1] 教育部高等教育司. 大学英语课程教学要求 $[M]$. 上海: 上海 外语教育出版社, 2007。

[2] Hutchinson, T. \& Water, A. English for Specific Purposes- A Learning-centered Approach [M]. Cambridge: CUP, 1987:56。

[3] 束定芳. 外语教学改革: 问题与对策 [M]. 上海: 上海外语教 育出版社, 2004:19。

[4] Gardner, D \& Miller, L. Establishing Self-access from Theory to Practice [M]. Cambridge: Cambridge University Press, 1999:7.

[5] 胡壮麟. 大学英语教学的个性化、协作化、模块化和超文本 化一一谈《教学要求》的基本理念 $[\mathrm{J}]$. 外语教学与研究, 2004, (5) : 345-350。

[6] 贾秋仙. 大学英语模块教学与形成性评价 $[J]$ 黑龙江教育学 院学报, 2009, (4) : 141-144。

[7] 蔡基刚. 基于需求分析的大学ESP课程模式研究 [J]. 外语教 学, $2012(3): 47-50$ 。

[8］晋艳. 大学英语四级后续课程设置的探索与实践 $[\mathrm{J}]$. 长春 教育学院学报, 2013 (5): 106-108。

[9] 蔡基刚. 后大学英语教改依据与对策研究 $[\mathrm{J}]$. 外语电化教 学, 2010(3):3-12。

[10］符雪青. 基于 “需求分析” 的大学英语后续选修课程的调 查研究与思考 $[\mathrm{J}]$. 外语电化教学, $2014(3)$ : 74-78。

[11] 赵庆红. 学生英语学习需求视角下的大学英语教学。

[12] 祝珣. 课程设置的学习者需求分析一一基于大学公共英语 课程的研究 $[\mathrm{J}]$. 外语界, 2014（6）：48-56。 